\title{
A metagenome for lacustrine Cladophora (Cladophorales) reveals remarkable diversity of eukaryotic epibionts and genes relevant to materials cycling
}

\begin{abstract}
Periphyton dominated by the cellulose-rich filamentous green alga Cladophora forms conspicuous growths along rocky marine and freshwater shorelines worldwide, providing habitat for diverse epibionts. Bacterial epibionts have been inferred to display diverse functions of biogeochemical significance: $\mathrm{N}$-fixation and other redox reactions, phosphorus accumulation, and organic degradation. Here, we report taxonomic diversity of eukaryotic and prokaryotic epibionts and diversity of genes associated with materials cycling in a Cladophora metagenome sampled from Lake Mendota, Dane Co., WI, USA, during the growing season of 2012. A total of 1,060 distinct 16S, 173 18S, and $35128 \mathrm{~S}$ rRNA operational taxonomic units, from which $>220$ genera or species of bacteria $(\sim 60)$, protists $(\sim 80)$, fungi (6), and microscopic metazoa ( 80), were distinguished with the use of reference databases. We inferred the presence of several algal taxa generally associated with marine systems and detected Jaoa, a freshwater periphytic ulvophyte previously thought endemic to China. We identified six distinct nifH gene sequences marking nitrogen fixation, >25 bacterial and eukaryotic cellulases relevant to sedimentary C-cycling and technological applications, and genes encoding enzymes in aerobic and anaerobic pathways for vitamin B12 biosynthesis. These results emphasize the importance of Cladophora in providing habitat for microscopic metazoa, fungi, protists, and bacteria that are often inconspicuous, yet play important roles in ecosystem biogeochemistry.
\end{abstract}

Keyword: Cellulases; Cladophora; Metagenome; Microbiome; Periphyton 